\title{
ATOMIC STRUCTURES AND COMPOSITIONS OF INTERFACES
}

\author{
Progress Report \\ for Period September 1, 1989 to August 31, 1990
}

David N. Seidrnan

Northwestern University

Materials Science and Engineering Department

Evanston, Illinois 60208-3108

Karl I. Merkle

Argonne National Laboratory

Materials Science Division

Argonne, Illinois 60439.8269

September 1990

Prepared for

THE U.S. DEPARTMENT OF ENERGY

AGREEMENT NO. DE-FG02-89ER45403 


\title{
ATOMIC STRUCTURES AND COMPOSITIONS OF INTERNAL INTERFACES
}

\section{ARESEARCH RROGRESS REPOR'T FOR THE PERLOD I SEPTEMUBER 1989 TO 31 AUGUST 1290}

\author{
David N. Seidman, Principal Investigator \\ Materials Science and Engineering Department \\ Northwestern University \\ Evanston, IL 60208-9990 \\ (708) 491.4391 or -3575 \\ FAX: (708) 491.7820 \\ Karl L. Merkle, Co-Principal Investigator \\ Materials Science Division \\ Argonne National Laboratory
}

Argonne, IL 60439-8269

(708) $972-4990$

FAX: (708) 972-4798

\section{TABLE OF CONTENTS}

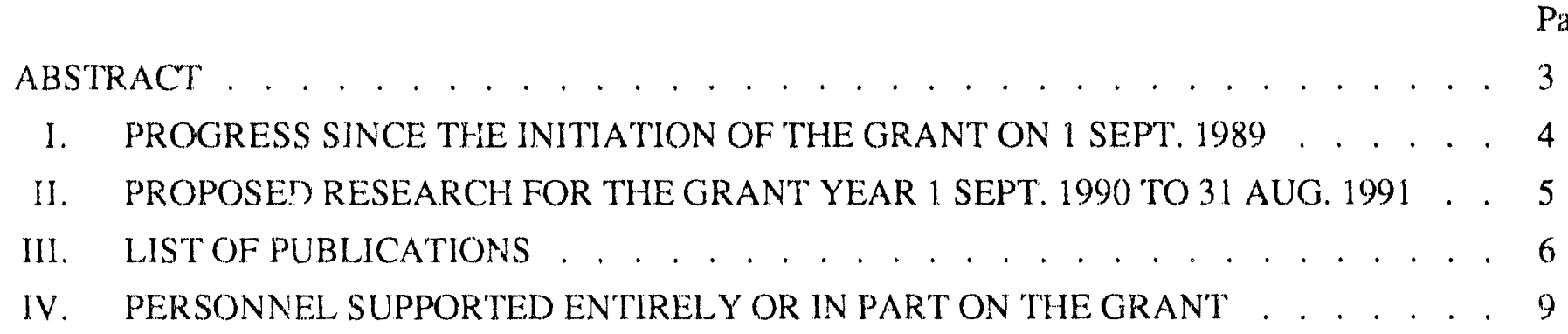




\section{ABSTRACT}

This research program focuses on an experimental study of the structure and chemistry of metal/metal oxide internal interfaces; the latter are mainly created, although not exclusively, by internal oxidation of binary or ternary metal alloys that are solid-solution phases prior to the internal oxidation treatment. The principal research tools are transmission electron microscopy (TEM), high resolution microscopy (HREM), analytical electron microscopy (AEM) and atom-probe field-ion microscopy (APFIM). The APFIM technique is uscu to determine the chemical composition of the interfacial region on ar atomic scale. Initial studies are focused on $\mathrm{Pd} / \mathrm{NiO}$, $\mathrm{Cu} / \mathrm{MgO}, \mathrm{Cu} / \mathrm{Al}_{2} \mathrm{O}_{3}, \mathrm{Cu} / \mathrm{SiO}_{2}$ interfaces, as well as metal oxides in Pt-based alloys. Topics of importance include coherency effects, misfit dislocations, structure of the terminating layer between the metal and the metal oxide, microstoichiometry, dipole space charge effects, and distributions of impurities and poirt defects at the interfacial region. 


\section{NOTICE}

This report was prepared as an account of work sponsored by the United States Government. Neither the United States nor the Department of Energy, nor any of their employees, nor any of their contractors, subcontractors, or their employees, makes any warranty, express or implied, or assumes any legal liability or responsibility for the accuracy, completeness, or usefullness of any information, apparatus, product or process disclosed or represents that its use would not infringe privately-owned rights. 


\section{Progress since the initiation of this grant on 1 September 1989.}

The initial experimental efforts on this new research program -- it was initiated 1 September 1989 -- are focused on obtaining a high number density $\left(\mathrm{N}_{\mathrm{d}}\right)\left[>5 \cdot 10^{16} \mathrm{~cm}^{-3}\right]$ of small metal-oxide precipitates $(10$ to $20 \mathrm{~nm}$ diam) in wire specimens that are suitable for combined transmission electron microscope (TEM) and atom-probe field-ion microscope (APFIM) studies. These requirements are essential, as the primary goal of our initial research is to deternine the chemical compositions of metal/metal oxide interfaces on an atomir. scale using the APFIM technique. The basic approach is to prepare binary metal alloys, for which the solute species has a greater affinity for oxygen than the solvent, and where the permeability of the oxygen $\left(c_{O} D_{O}\right)$ is greater than $c_{s} D_{S}$ for the solute elements -- s.[1,2] Our specific efforts have been as follows.

\section{M.S. Thesis research of M. Holzer}

The internal oxidation behavior of $\mathrm{Pd}(\mathrm{Cd})$ and $\mathrm{Pd}(\mathrm{Ni})$ was studied using a wide variety of characterization techniques. The particular alloys studied were: $\mathrm{Pd}-() .51,1.8,5.8$ and 10.3 at.\% $\mathrm{Cd}$; and $\mathrm{Pd} \cdot 1$ and 4 at.\% $\mathrm{Ni}$. Specimens of these alloys were studied employing optical microscopy to determine the internal oxidation kinetics, and thereby establish the time scale for obtaining metal oxide precipitates at a given denth in either thin foils or wires. These alloys were prepared in wire form in order to perform TEM and APFIM studies on the same specimen. We have succeeded in obtaining cadmium oxide $(\mathrm{CdO})$ and nickel oxide $(\mathrm{NiO})$ precipitates in thin films; selected area diffraction patterns were used to demonstrate that the oxides had these stoichiometries. Wire specimens containing large NiO oxide precipitates $(>30 \mathrm{~nm})$ were obtained, but the precipitates were invariably etched out. APFIM analyses were performed on the Pd-1 at.\% alloy and reasonably good mass spectra were obtained.

\section{Research of Dr. X.W. Lin and Mr. David K. Chan}

Additional APFIM experiments were performed on homogenized Pd-4 at.\% Ni specimens, and a concentration of $3.7 \pm 0.53$ at.\% Ni was measured. A problem with this Pd-based alloy is that the tips "jump" at the analyzing temperature $(45 \mathrm{~K})$-. - i.e., they field evaporate in an uncontrolled manner and form a completely new surface without warning. This phenomenon makes it difficult to examine routinely internally oxidized $\mathrm{Pd} / \mathrm{NiO}$ specimens, and therefore we decided to put effort into several other alloy systems to identify the metal/metal oxide system(s) that is (are) easiest to do research on.

It has been demonstrated that precipitates in internally oxidized $\mathrm{Cu}(\mathrm{Mg}), \mathrm{Cu}(\mathrm{Si})$ and $\mathrm{Cu}(\mathrm{Al})$ alloys can be 
imaged by FIM [3]. Specifically the precipitates had diameters in the range 1.7 to $5.2 \mathrm{~nm}$ for internal oxidation times of $<1$ hour at 700 or $8000^{\circ} \mathrm{C}$. Therefore we prepared $\mathrm{Cu}(\mathrm{Mg})$ alloys with concentrations of $0.25,1.05$ at. \% $\mathrm{Mg}$ by diluting a master alloy with a concentration of $10 \mathrm{at} \% \mathrm{Mg}$; the alloys were prepared by melting in a graphite crucible in a vacuum furnace under flowing Ar gas and then homogenizing them by arc melting, and annealing for $1 \mathrm{~J} \mathrm{~h}$ at $1273 \mathrm{~K}$. TEM specimens of these alloys were next internally oxidized at $1273 \mathrm{~K}$ for 0.5 or 2 $\mathrm{h}$ and for $2.5 \mathrm{~h}$ at $1073 \mathrm{~K}$ employing the so-called Rhines's pack. [4] In the specimens that were internally oxidized for $0.5 \mathrm{~h}$ at $12.73 \mathrm{~K}, \mathrm{MgO}$ precipitates with a diam of $\approx 2.5$ to $5 \mathrm{~nm}$ at $\mathrm{N}_{\mathrm{d}}=5.7 \cdot 10^{16} \mathrm{~cm}^{-3}$ were observed along with $\approx 35 \mathrm{~nm}$ diam precipitates at $\mathrm{N}_{\mathrm{d}}=1.4 \cdot 10^{15} \mathrm{~cm}^{-3}$. The specimen internally oxidized at 1273 $\mathrm{K}$ for $2 \mathrm{~h}$ exhibited $\mathrm{MgO}$ precipitates with $\mathrm{N}_{\mathrm{d}}=3.6 \cdot 10^{15} \mathrm{~cm}^{-3}$ at the surface. The specimen internally oxidized at $1073 \mathrm{~K}$ for $2.5 \mathrm{~h}$ exhibited a diam of $25 \mathrm{~nm}$ and a number density of $>3.6 \cdot 10^{15} \mathrm{~cm}^{-3}$ in the center of the foil. These results demonstrate that we will be able to perform combined TEM and APFIM on the Cu/MgO.

1. C. Wagner, Z. Metallk. 28, 368 (1959).

2. J. L. Meijering, in Advances in Materials Research, edited by H. Herman (J. Wiley \& Sons, New York, 1971), vol. 5, pp. 1-81.

3. D. J. Pedder, E. D. Boyes, and G. C. Smith, Metals Sci. 10, 4.37 (1976).

4. F. N. Rhines and A. H. Grobe, Trans. Amer. Inst. Min. (Metall.) Engrs. 147, 318 (1942).

\section{II.Proposed research for the grant year 1 September 1990 to 31 August 1991: Year two of the present grant.}

Some of the basic questions we are trying to answer concerning metal/metal oxide interfaces employing the atom-probe field microscope (APFIM) technique ${ }^{1}$ are as follows:

1. Which species of a metal oxide faces the metal matrix -- oxygen or metal; i.e, the chemical composition of the teminating layer?

2. Is the species of a metal oxide facing the metal matrix dependent upon the crystallography of the interface?

3. In the case of a semicoherent interface does the presence of the requisite misfit dislocations affect the nature of the chemical composition at an interface?

4. Are the metal oxide precipitates conpletely stoichiometric or is there a deviation from stoichiometry in the bulk of the precipitate or at the meial/metal oxide?

5. What is the nature of the chemical composition profile across a metal/metal oxide? Is it a very sharp twodimensional interface where the composition changes from metal to metal oxide in one interplanar spacing, or is the interface somewhat diffuse, or is there any evidence for an oscillatory behavior in the

\footnotetext{
IThe APFIM experiments are complemented and supplemented by the use of both conventional and high resolution electron microscope techniques.
} 
concentration profile of oxygen (metal) normal to the metal/metal oxide interface? The latter question is raised because we have recently observed an oscillatory profile at a $\Sigma \approx 5 / \approx(202)$ interface in a Pt-3 at.\% $\mathrm{Ni}$ alloy via APFIM and Monte Carlo computer simulations.[1]

6. Are the metal and oxygen atoms distributed uniformly in the plane of the interface, or are there point defects also present at an interface?

7. If a ternary alloy is internally oxidized and only one of the two solute elements is actually internally oxidized, then how is the unoxidized redistributed with respect to the metal/metal oxide interface?

We are continuing to study $\mathrm{Cu}(\mathrm{Mg})$ alloys -- and to a lesser degree $\mathrm{Pd}(\mathrm{NiO})$ alloys -- using both the TEM and APFIM techniques. In addition, research is commencing on platinum based alloys containing the elements $\mathrm{Sn}, \mathrm{In}, \mathrm{Ti}, \mathrm{Zr}, \mathrm{W}$ or $\mathrm{Al}$ in solid solution, as all of these elements have been shown to internally oxidize. [2] There is also some indirect evidence that a Pt-2 wt.\% $\mathrm{Ni}$ alloy internally oxidizes at $1402^{\circ} \mathrm{C}$ to form $\mathrm{NiO}$. [3] The study of Pt-based alloys is very amenable to the FIM technique and therefore they are interesting systems to pursue experimentally. [4-9]. The first research on Pt-based alloys is a study to determine which alloy is the most suitable for the APFIM technique and hence involves a survey study of the above alloys. After completion of the survey study we are going to focus our efforts on the most promising binary (or ternary) systems.

1. S. M. Kuo, A. Seki, Y. Oh, and D. N. Seidman, submitted to Phys. Rev. Lett. April (1990).

2. W. Betteridge and D. W. Rhys, in Proc. First Inter. Congress on Metallic Corrosion (London, April, 1961), pp. $186-192$.

3. L. R. Velho and R. W. Bartlett, Metall. Trans. 3, 65 (1972).

4. C.-G. Chen and R.W. Balluffi, Acta Metall. 23, 919 \& 931 (1975).

5. C.-Y. Wei and D.N. Seidman, Radiat. Effects 32, 229 (1977).

6. C.-Y. Wei and D.N. Seidman, J. Nucl. Mater. 69 \& 70, 693 (1978).

7. C...Y. Wei and D.N. Seidman, Phil. Mag. A, 37, 257 (1978).

8. D. Pramanik and D.N. Seidman, Appl. Phys. Lett. 43, 639 (1983).

9. D. Pramanik and D.N.Seidman, J. Appl. Phys. 60, 137 (1986).

\section{List of Publications}

1. Mark R. Holzer, M.S, thesis, Northwestern University, December 1989. "Palladium/Metal Oxide Interfaces: First Steps Towards Their Production and Study on an Atomic Scale." 


\section{PERSONNEL SUPPORTED ENTIRELY OR IN PART ON GRANT}

1. Professor David N. Seidman, Principal Investigator

2. Dr. X. W. Lin ${ }^{+}$, Research Associate I

3. Mr. David K. Chan ${ }^{++}$, B.S., Research Assistant

4. Mr. Yong Chen ${ }^{*}$, B.S., M.S., Research Assistant

5. Mr. Mark Holzer ${ }^{* *}$, B.S., M.S., Research Assistant

${ }^{+}$Dr.X. W. Lin received his Ph.D. degree from the University of Paris - South (Orsay) in solid-state physics and materials science in 1987, and worked with Prof. Seidman as a post-doctoral student prior to joining this grant as a Research Associate I. He has extensive experience with the transmission electron microscope technique, as a resu't of his Ph.D. thesis research and his recent research which employed the $1 \mathrm{MeV}$ electron microscope at the Argonne National Laboratory. Dr. Lin is performing full time research on this grant.

${ }^{++}$Mr. David K. Chan received his B.S. degree in applied and engineering physics from Cornell University in 1988 and he commenced his graduate studies at Northwestern University in September 1988; at Cornell he worked as an undergraduate assistant to Prof. John Silcox on the dedicated STEM. He has been supported by the Division of Educational Programs and the Materials Science Division at the Argonne National Laboratory since that date. Mr. Chan will finish all his course work by 1 June 1990 and will then be a full time researcher. He has commenced doing his Ph.D. thesis research on a part-time basis (20 hrs/wk).

${ }^{*}$ Mr. Yong Chen received B.S. and M.S. degrees in physics in 1985 and 1988, respectively, from Nanjing University. His research work involved surfaces and interfaces and he used the atom-probe field-ion microscope to several problems involving precipitation phenomena, and oxide films on metals. He was a visiting scholar at Pennsylvania State University, working with Prof. T. T. Tsong, prior to commencing his Ph.D. studies at Northwestern University. He is both taking graduate level courses and starting his Ph.D. thesis research.

** Mr. Mark Holzer received a B. S. degree from the University of Wisconsin-Milwaukee in 1987 prior to starting his M.S. studies at Northwestern University. He was supported by the Division of Educational Programs and the Materials Science Division at the Argonne National Laboratory for the duration of his M.S. studies. He received his M.S. degree in December 1989 from Northwestern University; his thesis is entitled "Palladium/Metal oxide Interfaces: First Steps Towards Their Production and Study on an Atomic Scale." Mr. Holzer took a position, as a research engineer, with the 3M Corporation in St. Paul, Minnesota upon the completion of his M.S. degree. 

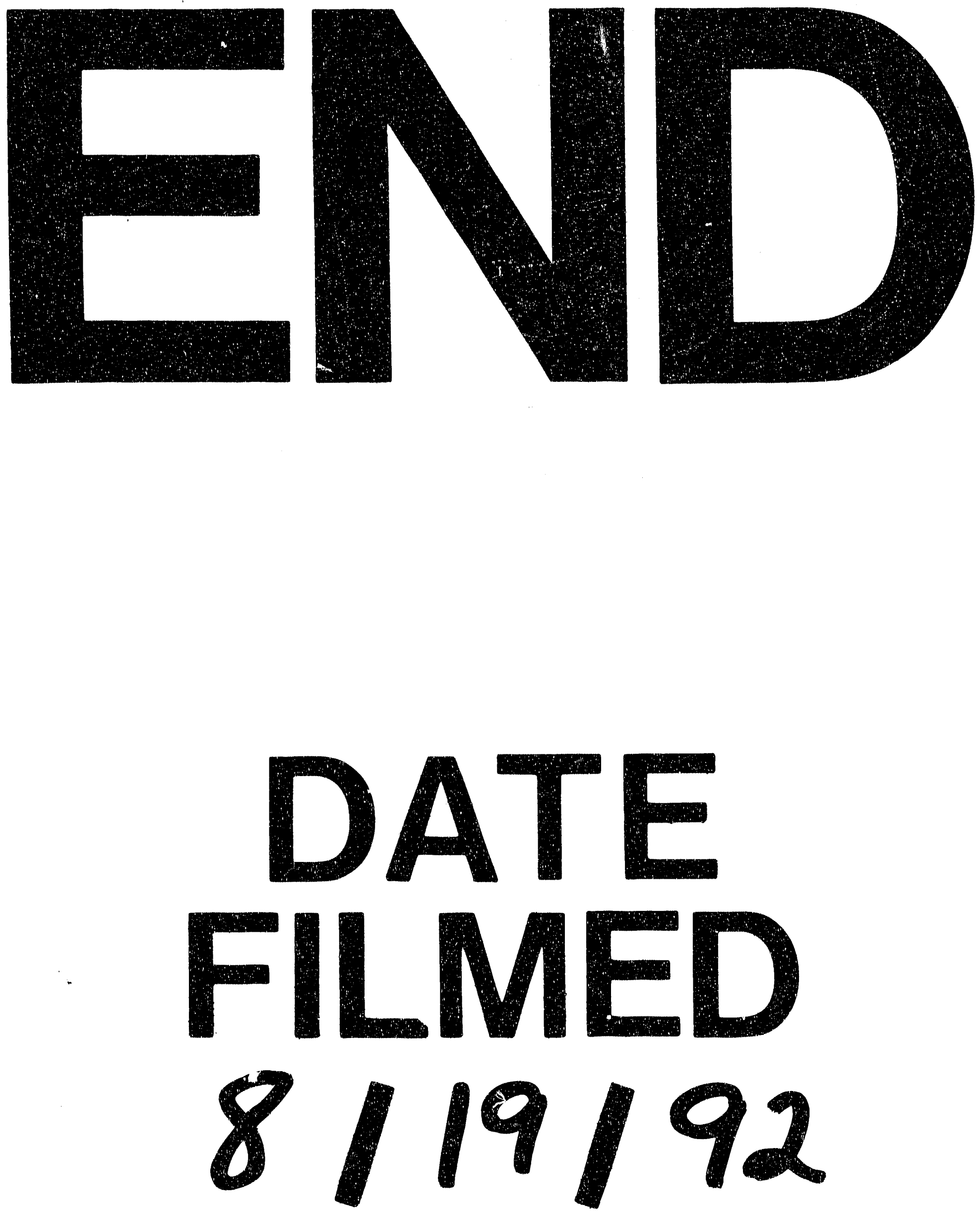

8 
